\title{
The SNM Practice Guideline for Somatostatin Receptor Scintigraphy $2.0^{*}$
}

\author{
Helena R. Balon ${ }^{1}$, Tracy L.Y. Brown ${ }^{2}$, Stanley J. Goldsmith ${ }^{3}$, Edward B. Silberstein ${ }^{4}$, Eric P. Krenning ${ }^{5}$, Otto Lang ${ }^{6}$, \\ Gary Dillehay ${ }^{7}$, Jennifer Tarrance, CNMT ${ }^{1}$, Matt Johnson, CNMT $^{1}$, and Michael G. Stabin ${ }^{8}$ \\ ${ }^{I}$ William Beaumont Hospital, Royal Oak, Michigan; ${ }^{2}$ University of Arkansas for Medical Sciences, Little Rock, Arkansas; ${ }^{3}$ New York \\ Hospital-Cornell Medical, New York, New York; ${ }^{4}$ University of Cincinnati Medical Center, Cincinnati, Ohio; ${ }^{5}$ Erasmus University \\ Medical Center, Rotterdam, The Netherlands; ${ }^{6} 3 \mathrm{rd}$ Medical School, Charles University, Prague, Czech Republic; ${ }^{7}$ Northwestern \\ University, Chicago, Illinois; and ${ }^{8}$ Vanderbilt University Medical Center, Nashville, Tennessee
}

VOICE Credit: This activity has been approved for 1.0 VOICE (Category A) credit. For CE credit, participants can access this activity on page 325 or on the SNM Web site (http://www.snm.org/ce_online) through December 31, 2013. You must answer $80 \%$ or the questions correctly to receive $1.0 \mathrm{CEH}$ (Continuing Education Hour) credit.

\section{PREAMBLE}

The Society of Nuclear Medicine (SNM) is an international scientific and professional organization founded in 1954 to promote the science, technology, and practical application of nuclear medicine. Its 16,000 members are physicians, technologists, and scientists specializing in the research and practice of nuclear medicine. In addition to publishing journals, newsletters, and books, the SNM also sponsors international meetings and workshops designed to increase the competencies of nuclear medicine practitioners and to promote new advances in the science of nuclear medicine.

The SNM will periodically define new practice guidelines for nuclear medicine practice to help advance the science of nuclear medicine and to improve the quality of service to patients throughout the United States. Existing practice guidelines will be reviewed for revision or renewal, as appropriate, on their fifth anniversary or sooner, if indicated.

Each practice guideline, representing a policy statement by the SNM, has undergone a thorough consensus process in which it has been subjected to extensive review, requiring the approval of the Committee on Guidelines and SNM Board of Directors. The SNM recognizes that the safe and effective use of diagnostic nuclear medicine imaging requires specific training, skills, and techniques, as described in each document. Reproduction or modifi-

\footnotetext{
Received Sep. 14, 2011; revision accepted Sep. 16, 2011.

For correspondence or reprints contact: Helena Balon, William Beaumont Hospital, 3601 W. Thirteen Mile Rd., Royal Oak, MI 48703.

E-mail: hbalon@beaumont.edu

${ }^{*}$ NOTE: FOR CE CREDIT, YOU CAN ACCESS THIS ACTIVITY THROUGH THE SNM WEB SITE (http://www.snm.org/ce_online) THROUGH DECEMBER 2013.

Published online Nov. 8, 2011.

COPYRIGHT (C) 2011 by the Society of Nuclear Medicine, Inc.

DOI: $10.2967 /$ jnmt.111.098277
}

cation of the published practice guideline by those entities not providing these services is not authorized.

These guidelines are an educational tool designed to assist practitioners in providing appropriate care for patients. They are not inflexible rules or requirements of practice and are not intended, nor should they be used, to establish a legal standard of care. For these reasons and those set forth below, the SNM cautions against the use of these guidelines in litigation in which the clinical decisions of a practitioner are called into question.

The ultimate judgment regarding the propriety of any specific procedure or course of action must be made by the physician or medical physicist in light of all the circumstances presented. Thus, there is no implication that an approach differing from the guidelines, standing alone, is below the standard of care. To the contrary, a conscientious practitioner may responsibly adopt a course of action different from that set forth in the guidelines when, in the reasonable judgment of the practitioner, such course of action is indicated by the condition of the patient, limitations of available resources, or advances in knowledge or technology subsequent to publication of the guidelines.

The practice of medicine involves not only the science, but also the art, of dealing with the prevention, diagnosis, alleviation, and treatment of disease. The variety and complexity of human conditions make it impossible to always reach the most appropriate diagnosis or to predict with certainty a particular response to treatment. Therefore, it should be recognized that adherence to these guidelines will not ensure an accurate diagnosis or a successful outcome. All that should be expected is that the practitioner will follow a reasonable course of action based on current knowledge, available resources, and the needs of the patient to deliver effective and safe medical care. The sole purpose of these guidelines is to assist practitioners in achieving this objective. 


\section{INTRODUCTION}

The purpose of this guideline is to assist nuclear medicine practitioners in recommending, performing, interpreting, and reporting the results of somatostatin receptor scintigraphy (SRS) with ${ }^{111}$ In-pentetreotide. The European Association of Nuclear Medicine guideline on ${ }^{111}$ In-pentetreotide scintigraphy (1) was taken into consideration throughout this guideline. This guideline covers imaging with only ${ }^{111}$ In-pentetreotide. Imaging with other somatostatin analogs is not a subject of this guideline.

\section{GOALS}

The goal of SRS is to detect and localize a variety of neuroendocrine tumors in patients often with elevated neuroendocrine tumor markers, as well as some nonneuroendocrine tumors. SRS may help in preoperative evaluation, staging, and restaging of these tumors.

\section{DEFINITIONS}

${ }^{111}$ In-pentetreotide is an agent used primarily for scintigraphic localization of primary and metastatic neuroendocrine tumors bearing somatostatin receptors. ${ }^{111}$ In-pentetreotide (OctreoScan; Covidien Inc.) is [ ${ }^{111} \mathrm{In}$-diethylenetriaminepentaacetic acid-D-Phe]octreotide, a somatostatin analog that binds to somatostatin receptors on cell surfaces. This octapeptide binds to somatostatin receptor-rich normal tissues and concentrates in neuroendocrine tumors and some nonneuroendocrine tumors containing somatostatin receptors (predominantly somatostatin receptor subtypes 2 and 5). Disorders that may be detected by SRS with ${ }^{111}$ In-pentetreotide include, but are not limited to, the following:

\section{A. Tumors with High Expression of Somatostatin Receptors}

1. Adrenal medullary tumors (pheochromocytoma, neuroblastoma, ganglioneuroma, paraganglioma)

2. Gastroenteropancreatic neuroendocrine tumors (formerly termed carcinoid, gastrinoma, glucagonoma, vasoactive intestinal polypeptide-secreting tumor, pancreatic polypeptide-secreting tumor, etc., or nonfunctioning gastroenteropancreatic tumors), more recently classified by the World Health Organization as low grade, intermediate grade and high grade (G1, G2, and G3)

3. Merkel cell tumor of the skin

4. Pituitary adenoma

5. Small-cell lung carcinoma

\section{B. Tumors with Low Expression of Somatostatin Receptors}

1. Astrocytoma

2. Benign and malignant bone tumors

3. Breast carcinoma

4. Differentiated thyroid carcinoma (papillary, follicular, Hürthle cell)
5. Lymphoma (Hodgkin and non-Hodgkin)

6. Melanoma

7. Meningioma

8. Non-small cell lung carcinoma

9. Prostate carcinoma

10. Renal cell carcinoma

11. Sarcomas

\section{Tumors with Variable Expression of Somatostatin Receptors (Especially Somatostatin Receptor Subtype 2)}

1. Insulinoma

2. Medullary thyroid carcinoma

\section{Nonneoplastic Processes}

1. Autoimmune diseases (e.g., rheumatoid arthritis, Graves' disease, Graves' ophthalmopathy)

2. Bacterial pneumonia

3. Cerebrovascular accident

4. Fibrous dysplasia

5. Granulomatous diseases (e.g., tuberculosis, sarcoid)

6. Postradiation inflammation

Thus, knowledge of the patient's medical history is important. In addition to these pathologies, normal organs such as the pituitary, thyroid, spleen, liver, and renal parenchyma also demonstrate avidity for ${ }^{111}$ In-pentetreotide. The gallbladder, bowel, renal collecting systems, ureters, and urinary bladder are seen as a result of tracer clearance.

\section{EXAMPLES OF CLINICAL AND RESEARCH INDICATIONS}

SRS may be used clinically for the following:

A. Detection and localization of suspected neuroendocrine and some nonneuroendocrine tumors and their metastases $(2-11)$

B. Staging of patients with neuroendocrine tumors $(7,12-$ 17)

C. Follow-up of patients with known disease to evaluate for progression or recurrence (restaging) $(10,12,17-20)$

D. Determination of somatostatin-receptor status (patients with somatostatin receptor-positive tumors may be more likely to respond to peptide receptor radionuclide therapy) (21-24)

E. Evaluation of acute inflammation in rheumatologic disorders (25-27)

Recommendation for appropriate use of SRS in the management of various neuroendocrine tumors and lung neuroendocrine tumors is addressed in the National Comprehensive Cancer Network Clinical Practice Guidelines in Oncology (17). 


\section{QUALIFICATIONS AND RESPONSIBILITIES OF PERSONNEL (IN THE UNITED STATES)}

Please see Section V of the SNM Procedure Guideline on General Imaging.

\section{PROCEDURE/SPECIFICATIONS OF THE EXAMINATION}

\section{A. Request}

The request should be made by a qualified physician or other licensed health-care professional familiar with the patient's clinical history. A relevant history; the type of suspected or known primary tumor; its hormonal activity; the results of other imaging studies (CT, MRI, ultrasound); laboratory results (tumor markers); history of recent surgery; and history of chemotherapy, radiation therapy, or octreotide therapy should be obtained. History of cholecystectomy and splenectomy should also be noted.

\section{B. Patient Preparation and Precautions}

When safe and appropriate, consideration should be given to discontinuing octreotide acetate therapy before ${ }^{111}$ In-pentetreotide administration in consultation with the referring clinician. The length of withdrawal will depend on the type (half-life) of the therapeutic agent; at least $1 \mathrm{~d}$ is recommended for standard agents and 4-6 wk for longacting/slow-release formulations.

To minimize radiation exposure, patients should be well hydrated before and for at least $1 \mathrm{~d}$ after tracer injection. The use of ${ }^{111}$ In-pentetreotide in patients with impaired renal function should be considered, as the rate of tracer excretion may be much slower than that in patients with normal renal function.

While there is no definitive literature on the use of ${ }^{111} \mathrm{In}$ pentetreotide in patients on dialysis, interpretable images may be obtained after dialysis.

The use of laxatives should be considered, especially when the abdomen is the area of interest. A mild oral laxative (e.g., bisacodyl or lactulose) may be administered in the evening before injection and in the evening following injection. The need for bowel preparation should be assessed on an individual basis, and laxatives should not be used in patients with active diarrhea or in patients with insulinoma.

For patients with suspected insulinoma, there is some controversy as to whether they need special attention during pentetreotide injection. The pentetreotide package insert states: "Since pentetreotide is an analog of octreotide, an intravenous line is recommended in any patient suspected of having an insulinoma. An intravenous solution containing glucose should be administered just before and during administration of Indium In-111 pentetreotide." While there have been no reports of hypoglycemic reactions in patients with insulinoma, each site should consider this caution and establish a local policy accordingly (15).

${ }^{111}$ In-pentetreotide should not be injected into intravenous lines used for, or together with, solutions for total parenteral nutrition (15).
${ }^{111}$ In-pentetretotide is classified as category $\mathrm{C}$ for use in pregnant women.

\section{Radiopharmaceuticals}

${ }^{111}$ In-pentetreotide is a standard somatostatin analog. The recommended administered activity is $222 \mathrm{MBq}$ $(6 \mathrm{mCi})$ in adults and $3 \mathrm{MBq} / \mathrm{kg}(0.08 \mathrm{mCi} / \mathrm{kg})$ in children. Based on in vitro studies, the hormonal effect of pentetreotide is approximately $10 \%$ that of octreotide. The amount of pentetreotide injected per dose of OctreoScan is $10 \mu \mathrm{g}$. This dose is not expected to have a clinically significant pharmacologic effect (except in insulinoma, see VI.B).

${ }^{111}$ In-pentetreotide is cleared rapidly from the blood pool (one third of the injected dose remains in the blood pool at $10 \mathrm{~min}, 1 \%$ at $20 \mathrm{~h}$ after injection). Excretion is almost entirely via the kidneys $(50 \%$ of the injected dose is recovered in the urine by $6 \mathrm{~h}, 85 \%$ within $24 \mathrm{~h}$ ). Hepatobiliary excretion represents about $2 \%$ of the administered dose. The biologic half-life is $6 \mathrm{~h}$. Adjustment of administered activity in patients with decreased renal function has not been studied.

\section{Protocol/Image Acquisition/Processing}

Patients should void before imaging.

\section{Imaging protocol}

Images are routinely acquired at $24 \mathrm{~h}$. Four-hour and 48-h postinjection imaging is optional. The delayed images may be needed to allow clearance of significant bowel activity. Four-hour images may be obtained to enable evaluation before the appearance of activity in the gut, but since tumor-to-background ratio is lower at $4 \mathrm{~h}$ than at 24 and $48 \mathrm{~h}$, some lesions may be missed at $4 \mathrm{~h}$. SPECT (or SPECT/CT if available) imaging is preferably performed at $24 \mathrm{~h}$ after injection because of the higher target-to-background ratio at that time. Early and delayed SPECT may be helpful in distinguishing physiologic bowel activity from pathologic lesions.

2. Image Acquisition

Planar images are acquired using a large-field-of-view $\gamma$-camera fitted with a medium-energy collimator. Symmetric $20 \%$ energy windows are centered over both photopeaks of ${ }^{111} \mathrm{In}$ (173 and $247 \mathrm{keV}$ ), and the data are summed. Planar localized images of the head, chest, abdomen, pelvis, and, if needed, extremities can be acquired for 1015 min per image, using a $512 \times 512$ or $256 \times 256$ matrix.

For whole-body images using a dual-head camera, it is suggested that anterior and posterior images are acquired into $2,048 \times 512$ or $1,024 \times 256$ matrices in a single pass at a speed that balances information density with practicability and patient comfort. Since cervical lymph node metastases may be missed on whole-body images, it is suggested that additional planar localized images of the head and neck, including lateral views, are obtained.

SPECT imaging of the appropriate regions, as indicated based on the clinical history or the planar images, is strongly recommended. It should be performed with a multidetector $\gamma$-camera when possible. Although imaging systems may 
vary, an example of potentially useful acquisition parameters for a multidetector system is $3^{\circ}$ angular sampling, $128 \times 128$ matrix, $360^{\circ}$ rotation, and $20-30 \mathrm{~s}$ per stop.

SPECT/CT imaging may help localize foci of abnormal tracer accumulation more accurately than planar imaging or SPECT alone and should be considered whenever indicated and available (28-30). The patient's history, planar images, and other prior imaging studies should be reviewed to determine which body areas may benefit from using SPECT/CT. However, to limit the radiation dose to the patient, CT performed as part of hybrid SPECT/CT should be used judiciously.

An example of potentially useful CT acquisition parameters for attenuation correction/anatomic localization performed as part of a hybrid SPECT/CT acquisition could include a $5.0-\mathrm{mm}$ slice thickness with a $2.5-\mathrm{mm}$ collimation for attenuation correction.

3. Image processing

Iterative reconstruction with ordered-subsets expectation maximization is the recommended reconstruction algorithm, as it may eliminate some of the artifacts seen with filtered backprojection in areas near intense tracer activity. Specific parameters depend on vendor recommendations and local preferences.

On completion, the processed data can be fused with CT data for attenuation correction and combined interpretation.

A low-count processing protocol should be considered when SPECT/CT is done in areas of low tracer activity. An algorithm is used to amplify the data, which are then processed and fused with the CT data.

For more information, see the SNM Procedure Guideline for General Imaging and the SNM Procedure Guideline for SPECT/CT.

\section{E. Interpretation}

When possible, images should be evaluated in conjunction with relevant anatomic images (e.g., CT, MRI, ultrasound). Where available, fusion imaging (SPECT/CT) should be considered for better characterization of tracer accumulation and more accurate lesion localization. The interpreting physician should carefully consider the clinical question raised in the request for ${ }^{111} \mathrm{In}$-pentetreotide imaging.

Images are best viewed using a computer display with individualized physician-directed optimization of intensity and contrast. Three-dimensional rendering of the SPECT data and its review in cinematic display are encouraged.

Knowledge of normal tissue accumulation of ${ }^{111}$ Inpentetreotide is important for study interpretation. This radiotracer can be seen in the pituitary, thyroid, liver, spleen, kidneys, bladder, and occasionally gallbladder. Intestinal activity is usually not present at $4 \mathrm{~h}$ but may be present at $24 \mathrm{~h}$; thus, 48 -h images may be necessary to clarify abdominal activity.

Additional issues to be taken into consideration include a comparison between pattern and intensity of uptake on early versus delayed images, the sensitivity of ${ }^{111}$ In-pentetreotide for the detection of the tumor type of interest as it relates to histology and expression/density of somatostatin receptor subtypes, and potential sources of false-negative and falsepositive results (see section IX).

\section{F. Clinical Utility in Specific Tumor Types}

1. Gastroenteropancreatic neuroendocrine tumors

In peptide hormone-producing gastroenteropancreatic endocrine tumors, including gastrinomas, insulinomas, vasoactive intestinal polypeptide-secreting tumors, glucagonomas, as well as nonfunctioning tumors, the sensitivity is generally high and varies depending on the tumor expression of somatostatin receptors. The sensitivity for insulinoma may be only $25 \%-60 \%$ because of the lower incidence of somatostatin receptors, especially subtype 2 $(7,9,30,31)$

2. Pheochromocytomas, neuroblastomas, and paragangliomas

In pheochromocytomas, neuroblastomas, and paragangliomas, sensitivity is greater than $85 \%$. Imaging with ${ }^{111}$ In-pentetreotide may be particularly useful in detecting primary lesions and metastases in unexpected (extraadrenal) sites not investigated by CT or MRI, when multiple tumors are suspected, or if conventional anatomic imaging is negative or equivocal. Tumors in the adrenal glands may be difficult to detect because of high renal activity; imaging with ${ }^{123} \mathrm{I}$ - or ${ }^{131} \mathrm{I}$-metaiodobenzylguanidine may therefore be preferable for tumor localization in the adrenal area (32). ${ }^{111} \mathrm{In}$-pentetreotide and ${ }^{123} \mathrm{I} /{ }^{131} \mathrm{I}$-metaiodobenzylguanidine have complementary roles in the evaluation of malignant pheochromocytomas, neuroblastomas, and paragangliomas (33).

\section{Medullary thyroid carcinoma}

In medullary thyroid carcinoma, sensitivity is $50 \%-75 \%$ (9,31). The use of SPECT/CT (for liver metastases) or comparison with ${ }^{123}$ I-sodium iodide scintigraphy (for intrathyroidal tumors) may increase the rate of lesion detection, especially when the uptake of ${ }^{111}$ In-pentetreotide in these organs is homogeneous. ${ }^{111}$ In-pentetreotide may be considered for imaging of the oxyphil variant of follicular cellderived thyroid cancers (34).

\section{Carcinoid tumors}

In carcinoid tumors, sensitivity is $86 \%-95 \%$. For extrahepatic lesions larger than $1 \mathrm{~cm}$ in diameter, sensitivity may exceed $90 \%$. Hepatic lesions may appear isointense relative to surrounding liver parenchyma; therefore, SPECT (with or without CT) imaging of the liver is recommended even if planar images appear normal. Sensitivity is lower for poorly differentiated (atypical) carcinoid tumors.

\section{Intracranial tumors}

In meningioma, sensitivity and specificity of $100 \%$ and $50 \%$, respectively, have been reported by some (35). Medulloblastoma sensitivity is $61 \%-93 \% .{ }^{111}$ In-pentetreotide scintigraphy may be used for postoperative follow-up of meningioma. Grade I and II astrocytomas are also somatostatin receptor-positive, grade III astrocytomas may or may 
TABLE 1

Radiation Dosimetry: Adults*

\begin{tabular}{|c|c|c|c|c|c|c|}
\hline \multirow[b]{2}{*}{ Radiopharmaceutical } & \multicolumn{2}{|c|}{$\begin{array}{l}\text { Administered } \\
\text { activity }\end{array}$} & \multicolumn{2}{|c|}{$\begin{array}{l}\text { Spleen (organ receiving } \\
\text { largest dose) }\end{array}$} & \multicolumn{2}{|c|}{$\begin{array}{l}\text { Effective } \\
\text { dose }\end{array}$} \\
\hline & $\overline{\mathrm{MBq}}$ & $\mathrm{mCi}$ & $\mathrm{mGy} / \mathrm{MBq}$ & $\mathrm{rad} / \mathrm{mCi}$ & $\mathrm{mSv} / \mathrm{MBq}$ & $\mathrm{rem} / \mathrm{mCi}$ \\
\hline${ }^{111}$ In-pentetreotide & 222 & 6 & 0.57 & 2.1 & 0.054 & 0.20 \\
\hline
\end{tabular}

not be, and grade IV astrocytomas (glioblastoma multiforme) are typically somatostatin receptor-negative. Localization of ${ }^{111}$ In-pentetreotide in an astrocytoma also requires that the blood-brain barrier be impaired.

\section{DOCUMENTATION/REPORTING}

In addition to the general information to be provided in each nuclear medicine report as recommended in the SNM Guideline on General Imaging, it is suggested that the report contain the following information:

\section{A. Indication}

The report should include clinical findings, results of laboratory tests (e.g., neuroendocrine tumor markers, if applicable), or results of other imaging studies, as well as other relevant history (known tumor and its type, recent radiation therapy, chemotherapy).

\section{B. Relevant Medications}

The report should describe relevant medications, including octreotide therapy and the length of time since it was discontinued, chemotherapy, and laxatives, if given.

\section{Procedure Description}

The procedure should be described, including the timing of imaging relative to radiopharmaceutical administration; areas imaged; whether SPECT or SPECT/CT was performed, and its timing and body areas included.

\section{Study Limitations}

The referring physician may be reminded that some tumors can lack somatostatin receptors or the appropriate receptor subtypes and, therefore, might not be detected. The differential diagnosis should consider the many potential causes for a false-positive study, as listed in section IX.D.

\section{EQUIPMENT SPECIFICATION}

A $\gamma$-camera (preferably dual-head) with medium-energy collimation should be used. The use of a hybrid SPECT/CT camera is strongly encouraged for selected body areas, when available and indicated.

\section{QUALITY CONTROL AND IMPROVEMENT, SAFETY, INFECTION CONTROL, AND PATIENT EDUCATION CONCERNS}

Before the administration of ${ }^{111}$ In-pentetreotide, the radiochemical purity of the preparation should be tested according to the manufacturer's instructions. The product should not be used if radiochemical purity is less than $90 \%$.

The radiopharmaceutical should be stored at or below $25^{\circ} \mathrm{C}\left(77^{\circ} \mathrm{F}\right)$ between preparation and administration and should be used within $6 \mathrm{~h}$ of preparation (15).

${ }^{111}$ In-pentetreotide should be inspected visually before administration. Preparations containing particulate matter or color should not be administered.

\section{A. Potential Causes for a False-Positive Interpretation}

Accumulation of ${ }^{111}$ In-pentetreotide in the nasopharynx and pulmonary hilar areas may be seen with respiratory infections.

Diffuse pulmonary or pleural accumulation of ${ }^{111} \mathrm{In}$ pentetreotide can be observed following radiation therapy to the lung or bleomycin therapy.

The tracer may accumulate at recent surgical and colostomy sites.

Accumulation of the tracer in normal structures (pituitary, thyroid, liver, spleen, kidneys, bowel, gallbladder, ureters, bladder, stimulated adrenal glands) and in multiple nonneoplastic disorders (some listed in Section III.C) must

TABLE 2

Radiation Dosimetry: 15-Year-Old Children*

\begin{tabular}{|c|c|c|c|c|c|c|}
\hline \multirow[b]{2}{*}{ Radiopharmaceutical } & \multicolumn{2}{|c|}{$\begin{array}{l}\text { Weight-adjusted } \\
\text { administered } \\
\text { activity }\end{array}$} & \multicolumn{2}{|c|}{$\begin{array}{l}\text { Spleen (organ receiving } \\
\text { largest dose) }\end{array}$} & \multicolumn{2}{|c|}{$\begin{array}{l}\text { Effective } \\
\text { dose }\end{array}$} \\
\hline & $\mathrm{MBq} / \mathrm{kg}$ & $\mathrm{mCi} / \mathrm{kg}$ & mGy/MBq & $\mathrm{rad} / \mathrm{mCi}$ & $\overline{\mathrm{mSv}} / \mathrm{MBq}$ & $\mathrm{rem} / \mathrm{mCi}$ \\
\hline${ }^{111}$ In-pentetreotide & 3 & 0.08 & 0.79 & 2.9 & 0.071 & 0.26 \\
\hline
\end{tabular}


TABLE 3

Radiation Dosimetry: 5-Year-Old Children*

\begin{tabular}{|c|c|c|c|c|c|c|}
\hline \multirow[b]{2}{*}{ Radiopharmaceutical } & \multicolumn{2}{|c|}{$\begin{array}{l}\text { Weight-adjusted } \\
\text { administered } \\
\text { activity }\end{array}$} & \multicolumn{2}{|c|}{$\begin{array}{l}\text { Spleen (organ receiving } \\
\text { largest dose) }\end{array}$} & \multicolumn{2}{|c|}{$\begin{array}{l}\text { Effective } \\
\text { dose }\end{array}$} \\
\hline & $\mathrm{MBq} / \mathrm{kg}$ & $\mathrm{mCi} / \mathrm{kg}$ & mGy/MBq & $\mathrm{rad} / \mathrm{mCi}$ & $\mathrm{mSv} / \mathrm{MBq}$ & $\mathrm{rem} / \mathrm{mCi}$ \\
\hline${ }^{111} / \mathrm{n}$-pentetreotide & 3 & 0.08 & 1.8 & 6.7 & 0.16 & 0.59 \\
\hline
\end{tabular}

*Adapted from ICRP 106 (37).

be kept in mind. Caution must be used to avoid interpreting physiologic gallbladder activity as hepatic metastasis.

In breast-feeding women, physiologic uptake may be seen in the breast.

\section{B. Potential Causes for a False-Negative Interpretation}

The presence of unlabeled somatostatin, either as a result of octreotide therapy (patients will often have decreased tracer localization to the spleen) or production of somatostatin by the tumor itself, may lower tumor detectability.

The absence of somatostatin receptor subtype 2, variable tumor differentiation, and variable receptor expression also influence tumor detectability. This is a consideration especially with insulinomas and medullary thyroid carcinomas.

Low target-to-background ratio may cause a falsenegative interpretation. Small liver metastases of neuroendocrine tumors may appear isointense relative to surrounding normal liver. Correlation with anatomic imaging, SPECT/CT, or subtraction scintigraphy with sulfur colloid may be considered in such cases.

\section{RADIATION SAFETY IN IMAGING}

See also Section $\mathrm{X}$ of the SNM Guideline for General Imaging.

It is the position of SNM that patient exposure to ionizing radiation should be at the minimum level consistent with obtaining a diagnostic examination. Reduction in patient radiation exposure may be accomplished by administering less radiopharmaceutical when the technique or equipment used for imaging can support such an action. Each patient procedure is unique, and the methodology to achieve minimum exposure while maintaining diagnostic accuracy needs to be viewed in this light. Radiopharmaceutical dose ranges outlined in this document should be considered as a guide. Dose reduction techniques should be used when appropriate. The same principles should be applied when CT is used in a hybrid imaging procedure. CT acquisition protocols should be optimized to provide the information needed while minimizing patient radiation exposure. In particular, dose reduction in pediatric imaging is always desirable, as long as image quality is maintained (36). Tables 1-3 summarize the radiation dosimetry for adults, 15-y-old children, and 5-y-old children. For the pregnant or potentially pregnant patient, Table 4 provides dose estimates to the fetus (no information about possible placental crossover of this compound was available). For the breastfeeding patient, International Commission on Radiological Protection (ICRP) Publication 106, Appendix D (37), suggests that no interruption of breastfeeding is needed for ${ }^{111}$ In-pentetreotide.

\section{ISSUES REQUIRING FURTHER CLARIFICATION}

Since ${ }^{111}$ In-pentetreotide elimination in patients with impaired renal function has not been studied, possible adjustment of administered activity in these patients needs to be clarified.

The role of ${ }^{111}$ In-pentetreotide scintigraphy in breast carcinoma, renal cell carcinoma, Hodgkin and non-Hodgkin lymphoma, and other tumors (see section III), as well as in the evaluation and management of some granulomatous and autoimmune processes (e.g., activity of sarcoidosis, response of Graves' ophthalmopathy to steroids, etc.) is yet to be determined.

Recent studies have suggested that imaging with ${ }^{111} \mathrm{In}$ pentetreotide and ${ }^{18} \mathrm{~F}-\mathrm{FDG}$ PET may be complementary and that abnormalities on either imaging modality predict a worse outcome in patients with neuroendocrine tumors. Further work is needed $(38,39)$.

Neuroendocrine tumor imaging with conjugates of octreotide labeled with positron emitters (e.g., ${ }^{68} \mathrm{Ga}-$ DOTATOC) may have higher sensitivity and accuracy when compared with ${ }^{111}$ In-pentetreotide; this issue requires further study (40).

The potential improvement in sensitivity and specificity of imaging such a heterogeneous group of tumors with a

TABLE 4

Dose Estimates to the Fetus (41)

\begin{tabular}{lcccc}
\hline Stage of gestation & $\mathrm{mGy} / \mathrm{MBq}$ & $\mathrm{rad} / \mathrm{mCi}$ & $\mathrm{mGy}$ & $\mathrm{rad}$ \\
\hline Early & 0.082 & 0.30 & 18 & 1.8 \\
$3 \mathrm{mo}$ & 0.060 & 0.22 & 13 & 0.13 \\
$6 \mathrm{mo}$ & 0.035 & 0.13 & 7.8 & 0.78 \\
$9 \mathrm{mo}$ & 0.031 & 0.11 & 6.9 & 0.69 \\
\hline
\end{tabular}


variable expression of different somatostatin receptor subtypes will depend on the future development and availability of a larger variety of radiopharmaceuticals (labeled either with single-photon emitters or positron emitters).

\section{ACKNOWLEDGMENTS}

The Committee on SNM Guidelines consists of the following individuals: Kevin J. Donohoe, MD (Chair) (Beth Israel Deaconess Medical Center, Boston, MA); Sue Abreu, MD (Sue Abreu Consulting, Nichols Hills, OK); Twyla Bartel, DO (UAMS, Little Rock, AR); Paul E. Christian, CNMT, BS, PET (Huntsman Cancer Institute, University of Utah, Salt Lake City, UT); S. James Cullom, PhD (Cardiovascular Imaging Technology, Kansas City, MO); Dominique Delbeke, MD, PhD (Vanderbilt University Medical Center, Nashville, TN); Vasken Dilsizian, MD (University of Maryland Medical Center, Baltimore, MD); Kent Friedman, MD (NYU School of Medicine, New York, NY); Jay A. Harolds, MD (OUHSC-Department of Radiological Science, Edmond, OK); Aaron Jessop, MD (Vanderbilt University Medical Center, Nashville, TN); J. Anthony Parker, MD, PhD (Beth Israel Deaconess Medical Center, Boston, MA); Rebecca A. Sajdak, CNMT, FSNMTS (Loyola University Medical Center, Maywood, IL); Heiko Schoder, MD (Memorial Sloan-Kettering Cancer Center, New York, NY); Barry L. Shulkin, MD, MBA (St. Jude Children's Research Hospital, Memphis, TN); Michael G. Stabin, PhD (Vanderbilt University, Nashville, TN); Mark Tulchinsky, MD (Milton S. Hershey Med Center, Hershey, PA); and Jerold W. Wallis, MD (Mallinckrodt Institute of Radiology, St. Louis, MO).

\section{REFERENCES}

1. Bombardieri E, Ambrosini V, Aktolun C, et al. ${ }^{111}$ In-pentetreotide scintigraphy: procedure guidelines for tumour imaging. Eur J Nucl Med Mol Imaging. 2010;37:1441-1448.

2. Gibril F, Reynolds JC, Chen CC, et al. Specificity of somatostatin receptor scintigraphy: a prospective study and effects of false-positive localizations on management in-patients with gastrinomas. J Nucl Med. 1999;40:539-553.

3. Gibril F, Reynolds JC, Doppman JL, et al. Somatostatin receptor scintigraphy: its sensitivity compared with that of other imaging methods in detecting primary and metastatic gastrinomas. Ann Intern Med. 1996;125:26-34.

4. Jamar F, Fiasse R, Leners N, et al. Somatostatin receptor imaging with ${ }^{111}$ indium pentetreotide in gastroenteropancreatic neuroendocrine tumors: safety, efficacy and impact on patient management. J Nucl Med. 1995;36:542-549.

5. Reisinger I, Bohuslavitzki KH, Brenner W, et al. Somatostatin receptor scintigraphy in small-cell lung cancer: results of a multicenter study. J Nucl Med. 1998;39:224-227.

6. Schmidt M, Scheidhauer K, Luyken C, et al. Somatostatin receptor imaging in intracranial tumours. Eur J Nucl Med. 1998;25:675-686.

7. Goldsmith SJ. Update on nuclear medicine imaging of neuroendocrine tumors. Future Oncol. 2009;5:75-84

8. Timmers HJLM, Chen CC, Carasquillo JA, et al. Comparison of F-18-fluoro-LDOPA, F-18-fluoro-deoxyglucose, and F-18-fluorodopamine PET and I-123 MIBG scintigraphy in the localization of pheochromocytoma and paraganglioma. J Clin Endocrinol Metab. 2009;94:4757-4767.

9. Krenning EP, Kwekkeboom DJ, Bakker WH, et al. Somatostatin receptor scintigraphy with [In-111-DTPA-d-Phe1] and [I-123-Tyr3]-octreotide: the Rotterdam experience with more than 1000 patients. Eur J Nucl Med. 1993;20:716-731.
10. Yüksel M, Lutterbey G, Biersack HJ, et al. ${ }^{111}$ In-pentetreotide in medulloblastoma: a comparison with magnetic resonance imaging. Acta Oncol. 2007;46: $111-117$.

11. Duet M, Sauvaget E, Petelle B, et al. Clinical impact of somatostatin receptor scintigraphy in the management of paragangliomas of the head and neck. $J$ Nucl Med. 2003;44:1767-1774.

12. Kwekkeboom DJ, Krenning EP, Scheidhauer K, et al. European Neuroendocrine Tumor Society (ENETS) consensus guidelines for the standards of care in neuroendocrine tumors: somatostatin receptor imaging with ${ }^{111} \mathrm{In}$-pentetreotide. Neuroendocrinology. 2009;90:184-189.

13. Hochstenbag MM, Heidendal GAK, Wouters EFM, et al. ${ }^{111}$ In-octreotide imaging in staging of small cell lung cancer. Clin Nucl Med. 1997;22:811-816.

14. Lebtahi R, Cadiot G, Sarda L, et al. Clinical impact of somatostatin receptor scintigraphy in the management of patients with neuroendocrine gastroenteropancreatic tumors. J Nucl Med. 1997;38:853-858.

15. OctreoScan [package insert]. Loma Linda, CA: Mallinckrodt Medical Inc.; October 2006.

16. Olsen JO, Pozderac RV, Hinkle G, et al. Somatostatin receptor imaging of neuroendocrine tumors with ${ }^{111}$ indium pentetreotide (OctreoScan). Semin Nucl Med. 1995;25:251-261.

17. National Comprehensive Cancer Network Web site. National Comprehensive Cancer Network (NCCN) Clinical Practice Guidelines in Oncology: neuroendocrine tumors, version 1.2011 [available at: http://www.nccn.org/ professionals/physician_gls/pdf/neuroendocrine.pdf. Accessed October 17, 2011], and small cell lung cancer, version 2.2012 [available at: http://www. nccn.org/professionals/physician_gls/pdf/sclc.pdf. Accessed October 17, $2011]$.

18. Khanna G, Bushnell D, O'Dorisio MS. Utility of radiolabeled somatostatin receptor analogues for staging/restaging and treatment of somatostatin receptorpositive pediatric tumors. Oncologist. 2008;13:382-389.

19. Klutmann S, Bohuslavizki KH, Brenner W, et al. Somatostatin receptor scintigraphy in postsurgical follow-up examinations of meningioma. J Nucl Med. 1998;39:1913-1917.

20. Khanna G, O'Dorisio MS, Menda Y, et al. Somatostatin receptor scintigraphy in surveillance of pediatric brain malignancies. Pediatr Blood Cancer. 2008; 50:561-566.

21. O'Dorisio MS, Kanna G, Bushnell D. Combining anatomic and molecularly targeted imaging in the diagnosis and surveillance of embryonal tumors of the nervous and endocrine systems in children. Cancer Metastasis Rev. 2008;27:665-677.

22. van Essen M, Krenning EP, Kam BLR, de Jong M, Valkema R, Kwekkeboom DJ. Peptide-receptor radionuclide therapy for endocrine tumors. Nat Rev Endocrinol. 2009;5:382-393.

23. Cavalla P, Schiffer D. Neuroendocrine tumors in the brain. Ann Oncol. 2001;12 (suppl 2):S131-S134.

24. Delpassand ES, Sims-Mourtada J, Saso H, et al. Safety and efficacy of therapy with high-activity ${ }^{111} \mathrm{In}$-pentetreotide in patients with progressive neuroendocrine tumors. Cancer Biother Radiopharm. 2008;23:292-300.

25. Kwekkeboom DJ, Krenning EP, Kho GS, et al. Somatostatin receptor imaging in patients with sarcoidosis. Eur J Nucl Med. 1998;25:1284-1292.

26. Kwekkeboom DJ, Krenning EP. Radiolabeled somatostatin analog scintigraphy in oncology and immune diseases: an overview. Eur Radiol. 1997;7:1103-1109.

27. Cascini GL, Cuccurullo V, Mansi L. The non-tumour uptake of ${ }^{111}$ In-octreotide creates new clinical indications in benign disease, but also in oncology. $\mathrm{QJ} \mathrm{Nucl}$ Med Mol Imaging. 2010;54:24-36.

28. Wong KK, Cahill JM, Frey KA, Avram AM. Incremental value of ${ }^{111} \mathrm{In}-$ pentetreotide SPECT/CT fusion imaging of neuroendocrine tumors. Acad Radiol. 2010;17:291-297.

29. Krausz Y, Keida Z, Kogan I, et al. SPECT/CT hybrid imaging with ${ }^{111}$ Inpentetreotide in assessment of neuroendocrine tumours. Clin Endocrinol (Oxf). 2003;59:565-573.

30. Goldsmith SJ, Mirtcheva R, Kostakoglu L. ${ }^{111}$ Indium octreotide SPECT/CT for neuroendocrine tumor imaging. In: Israel $\mathrm{O}$, Goldsmith SJ, eds. Hybrid SPECT/CT Imaging in Clinical Practice. Philadelphia, PA: Taylor and Francis; 2006:77-92.

31. Rufini V, Calcagni ML, Baum RP. Imaging of neuroendocrine tumors. Semin Nucl Med. 2006;36:228-247.

32. Torre JJ, Bloomgarden ZT, Dickey RA, et al. American Association of Clinical Endocrinologists medical guidelines for clinical practice for the diagnosis and treatment of hypertension. Endocr Pract. 2006;12:193-222.

33. Tenenbaum F, Lumbroso J, Schlumberger M, et al. Comparison of radiolabeled octreotide and meta-iodobenzylguanidine (MIBG) scintigraphy in malignant pheochromocytoma. J Nucl Med. 1995;36:1-6.

34. AACE/AAES medical/surgical guidelines for clinical practice: management of thyroid carcinoma. Endocr Pract. 2001;7:203-220. 
35. Nathoo N, Ugokwe K, Chang AS, et al. The role of ${ }^{111}$ indium-octreotide brain scintigraphy in the diagnosis of cranial, dural-based meningiomas. J Neurooncol. 2007;81:167-174.

36. Gelfand MJ, Parisi M, Treves ST. Pediatric radiopharmaceutical administered doses: 2010 North American Consensus Guidelines. J Nucl Med. 2011;52: 318-322.

37. International Commission on Radiological Protection. ICRP Publication 106: Radiation Dose to Patients from Radiopharmaceuticals-A Third Addendum to ICRP Publication 53. Philadelphia, PA: Elsevier; 2009.

38. Garin E, Le Jeune F, Devillers A, et al. Predictive value of ${ }^{18}$ F-FDG PET and somatostatin receptor scintigraphy in patients with metastatic endocrine tumors. J Nucl Med. 2009;50:858-864.

39. Zalom ML, Waxman AD, Yu R, et al. Metabolic and receptor imaging in patients with neuroendocrine tumors: comparison of fluorodeoxyglucose-positron emis- sion tomography and computed tomography with ${ }^{111}$ indium pentetreotide. Endocr Pract. 2009;15:521-527.

40. Gabriel M, Decristoforo C, Kendler D, et al. Ga-68 DOTA-Tyr3-octreotide PET in neuroendocrine tumors: comparison with somatostatin receptor scintigraphy and CT. J Nucl Med. 2007;48:508-518.

41. Russell JR, Stabin MG, Sparks RB, Watson EE. Radiation absorbed dose to the embryo/fetus from radiopharmaceuticals. Health Phys. 1997;73:756769.

\section{APPROVAL}

This practice guideline was approved by the Board of Directors of the SNM on July 19, 2011. 